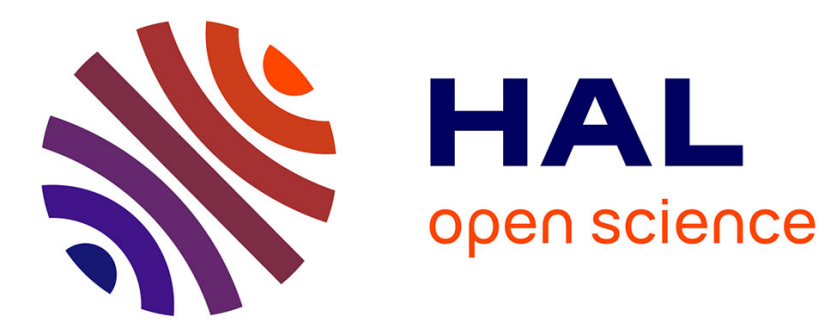

\title{
Endocannabinoids, sperm functions and energy metabolism
}

\author{
Rossato Marco
}

\section{To cite this version:}

Rossato Marco. Endocannabinoids, sperm functions and energy metabolism. Molecular and Cellular Endocrinology, 2008, 286 (1-2), 10.1016/j.mce.2008.02.013 . hal-00532003

\section{HAL Id: hal-00532003 https://hal.science/hal-00532003}

Submitted on 4 Nov 2010

HAL is a multi-disciplinary open access archive for the deposit and dissemination of scientific research documents, whether they are published or not. The documents may come from teaching and research institutions in France or abroad, or from public or private research centers.
L'archive ouverte pluridisciplinaire HAL, est destinée au dépôt et à la diffusion de documents scientifiques de niveau recherche, publiés ou non, émanant des établissements d'enseignement et de recherche français ou étrangers, des laboratoires publics ou privés. 


\section{Accepted Manuscript}

Title: Endocannabinoids, sperm functions and energy metabolism

Author: Rossato Marco

PII: $\quad$ S0303-7207(08)00086-5

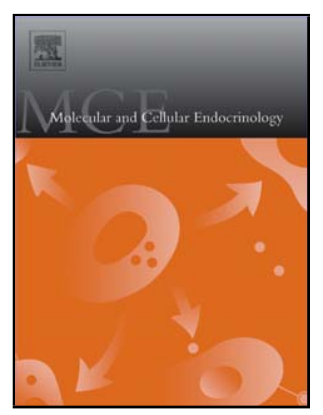

DOI: doi:10.1016/j.mce.2008.02.013

Reference: $\quad$ MCE 6823

To appear in: $\quad$ Molecular and Cellular Endocrinology

Received date: $\quad 22-1-2008$

Revised date: $\quad 15-2-2008$

Accepted date: $\quad 16-2-2008$

Please cite this article as: Marco, R., Endocannabinoids, sperm functions and energy metabolism, Molecular and Cellular Endocrinology (2007), doi:10.1016/j.mce.2008.02.013

This is a PDF file of an unedited manuscript that has been accepted for publication. As a service to our customers we are providing this early version of the manuscript. The manuscript will undergo copyediting, typesetting, and review of the resulting proof before it is published in its final form. Please note that during the production process errors may be discovered which could affect the content, and all legal disclaimers that apply to the journal pertain. 


\title{
ENDOCANNABINOIDS, SPERM FUNCTIONS AND ENERGY METABOLISM
}

\author{
Rossato Marco, MD, phD
}

\begin{abstract}
Endocrine-Metabolic Laboratory, Clinica Medica 3, Department of Medical and Surgical Sciences University of Padova, Padova-Italy
\end{abstract}

Address for correspondence:

Dr. Marco Rossato, MD, phD

University of Padova

Department of Medical and Surgical Sciences

Endocrine-Metabolic Laboratory

Clinica Medica 3

Via Ospedale 105

35128 Padova

Italy

Tel: +39.49.8218747

Fax: +39.49 .8213332$

e-mail: marco.rossato@unipd.it 


\begin{abstract}
Cannabinoids, the main active components of marijuana, have been shown to exert different adverse effects on male reproduction both in vertebrates and invertebrates. The main effects of endocannabinoids, a particular group of endogenously produced cannabinoids, in sperm are the inhibition of motility, capacitation and acrosome reaction, all fundamental processes necessary for oocyte penetration, whose alteration leads to the inhibition of sperm fertilizing ability. These inhibitory effects are mediated by the direct action of endocannabinoids on sperm through the activation of the cannabinoid receptor subtype 1 that has been shown to be expressed in mature sperm. In many different cell types it has been demonstrated that endocannabinoids negatively influence mitochondrial activity. In the present paper it will be briefly reviewed the role of endocannabinoids, on sperm motility, capacitation and acrosome reaction with particular attention on the possible interference of endocannabinoids with sperm mitochondrial activity.
\end{abstract}




\section{Introduction}

Over the last decade there has been a significant boost in the evaluation of the role of endocannabinoids in the regulation of mammalian reproduction above all after the identification of specific receptors for endocannabinoids and the demonstration that most species can produce different endocannabinoids such as anandamide (AEA) and 2-arachidonoylglycerol (2-AG) (Felder et al 1998). It is now well established that sperm express the cannabinoid receptor subtype 1 (CNR1) and its activation in vitro determines an inhibition of important sperm functions as well as motility, capacitation and acrosome reaction leading to the decrease of sperm fertilizing ability (Schuel et al 1994; Schuel et al 2002a; Maccarrone et al 2005; Rossato et al 2005; Cobellis et al 2006). The inhibitory effects of endocannabinoids on sperm functions have been observed in sperm from different species, from vertebrates to invertebrates (Schuel et al 1994; Maccarrone et al 2005; Rossato et al 2005; Cobellis et al 2006; Whan et al 2006). The effects of endocannabinoids present in marijuana smokers on different body functions are well known since thousands of years ago and the similarity of the mechanism of action of these substances in sperm from such distant phylogenetical species, suggest the possible importance of the "cannabinoid system" in the regulation of sperm functions and reproduction (Di Marzo 2006). While the inhibitory effects of endocannabinoids on sperm motility have been consistently reported in sperm from different species (Schuel et al 1994; Maccarrone et al 2005; Rossato et al 2005; Cobellis et al 2006; Whan et al 2006), the mechanisms mediating these effects have not been elucidated yet although 
it has been suggested a possible interference with the energy metabolism (Rossato et al 2005).

In the present paper it will be briefly reviewed the role of energy metabolism in sperm physiology and the effects of endocannabinoids on sperm motility, capacitation and acrosome reaction discussing the possible interference with the production of energetic substrates as the pathogenetic mechanism leading to sperm functions inhibition by endocannabinoids.

\section{Endocannabinoids and sperm motility}

Since the first report published by Perez et al. in 1981 (Perez et al 1981), experimental data have accumulated confirming that endocannabinoids negatively influence the motility of sperm in different mammalian species. Apart from observations obtained in sea urchin showing no significant effects of endocannabinoids on sperm motility (Schuel et al 1994), these substances inhibit sperm motility in different mammalian species including man (Maccarrone et al 2005; Rossato et al 2005; Whan et al 2006). While the observations on the negative effects of endocannabinoids on sperm motility have been reported in the mid '70s and early ' 80 s, the identification of the existence of two receptors for cannabinoids, namely CNR1 and CNR2, came in the early '90s with the demonstration of the expression of the CNR1 also in the testis (Gerard et al 1991). Only recently by means of pharmacological experimental approach, the inhibitory effects of endocannabinoids on mammalian sperm motility have been identified as due to CNR1 activation (Maccarrone et al 2005; Rossato et al 2005). Very recently Cobellis et al. replicated these results in sperm from Rana esculenta 
utilizing the same pharmacological approach (Cobellis et al 2006). Furthermore the same Authors extended these observations by means of an elegant molecular genetic experimental approach showing that sperm from CNRI KO mice show an dramatical increase of motile sperm cells already in the caput epididymis clearly demonstrating that the lack of CNR 1 signalling importantly affects the gradual acquisition of sperm motility (Ricci et al 2007). Then, although the studies evaluating the effects of endocannabinoids on sperm motility are not abundant, it seems that in general the activation of CNR1 inhibits motility in invertebrate and vertebrate sperm at least in vitro. On the contrary, contradictory results have been reported regarding the effects of endocannabinoids assumption, as well as marijuana smoking, on human sperm motility in vivo due probably to the experimental design or to the small number of subjects participating to the different clinical studies (Hembree et al 1978).

\section{Endocannabinoids and sperm capacitation}

After ejaculation, sperm have not yet acquired the fertilizing ability and they have to undergo a complex and still unclear series of biochemical and morphological events collectively known as capacitation (Yanagimachi 1994). In particular, a characteristic process of capacitation consists in a remodeling of the lipid plasma membrane that seems to improve the ability of sperm to respond to stimuli inducing the acrosome reaction. These changes are activated by still not fully elucidated mechanisms involving the adenylate cyclase/cAMP/PKA signaling pathway which activation leads to tyrosine phosphorylation of different proteins 
(Beltran et al 2007; De Jonge et al 1991; Salicioni et al 2007; Wassarman et al 2005). These processes are inhibited by endocannabinoids via CNRI activation and are specific since they are counteracted by sperm pre-incubation with the CNR 1 antagonist SR 141716 (Maccarrone et al 2005; Rossato et al 2005). Physiologically, sperm capacitation occurs within the female genital tract and it has been demonstrated that sperm leaving seminal plasma and reaching the uterus and oviduct swim in a external milieu presenting progressively reduced concentrations of endocannabinoids (Schuel et al 2002b). Then, as sperm approach the egg, they encounter the lowest concentrations of endocannabinoids present in the female genital tract thus suggesting that the activation of the endocannabinoid system in sperm seems to maintain the sperm in a quiescent "uncapacitated" condition before interacting with the egg (Schuel et al 2002b; Rossato et al 2005; Whan et al 2006).

\section{Endocannabinoids and sperm acrosome reaction}

Sperm capacitation is the fundamental pre-requisite for the ability of sperm to undergo the exocytosis of the acrosome, a specialized secretory granule located at the apex of sperm head (Yanagimachi 1994) containing different proteolytic enzymes necessary for the sperm penetration of the egg's coats. This reaction permits sperm attachment and fusion of egg and sperm plasma membranes and then fertilization (Wassarman et al 2005; Salicioni et al 2007). Sperm that do not undergo the acrosome reaction are not able to bind to the egg's zona pellucida and cannot fertilize it. According to the inhibitory effects of endocannabinoids on sperm capacitation, substantially homogeneous data exist indicating that CNR 1 
activation reduce the ability of sperm to undergo acrosome reaction both in vertebrate and invertebrates (Schuel et al 1994; Schuel et al 2002a; Maccarrone ef al 2005; Rossato et al 2005; Whan et al 2006). Importantly endocannabinoids do not affect fertility of eggs thus showing that these effects are directed only to sperm (Schuel et al 1994; Schuel et al 2002a). The mechanisms activated by endocannabinoids determining the inhibition of the sperm acrosome reaction are still unknown. It is well known that ion channels and regulation of ion fluxes through the sperm plasma membrane are crucial for the acrosome reaction and the most important physiological regulator appears to be calcium $\left(\mathrm{Ca}^{2+}\right)$ signalling (Foresta and Rossato 1997; Darszon et al 1999). To this regard we have previously shown that the endocannabinoid AEA did not modify the intracellular $\mathrm{Ca}^{2+}$ concentrations in human sperm thus possibly ruling out any interfering effect of endocannabinoids on $\mathrm{Ca}^{2+}$ signaling (Rossato et al 2005). It is well known that CNR1 is a G-protein coupled receptor that has been shown to inhibit adenylate cyclase activity (Pertwee 1997; Di Marzo et al 2005). Adenylate cyclase/cAMP/protein kinase A pathway plays an important role in the sperm capacitation and acrosome reaction: intracellular levels of cAMP rise during acrosome reaction, cell permeant cAMP analogues induce the acrosome reaction, pharmacological inhibitors of CAMP-dependent PKA reduce this exocytotic event supporting a role for the adenylate cyclase/cAMP/PKA system in the signaling pathway leading to sperm acrosome reaction and egg fertilization (De Jonge et al 1991; Wassarman et al 2005; Beltran et al 2007; Salicioni et al 2007). The inhibitory effects of endocannabinoids on this fundamental signalling pathway as recently described in mammalian sperm (Maccarrone et al 2005) may explain 
the negative actions of these agents activating the CNRI on sperm capacitation and acrosome reaction.

\section{Sperm energy metabolism}

Energy metabolism is the fundamental process supporting all cell functions and it is perhaps more important in sperm that are specialized motile cells that have to move rapidly to encounter and fertilize the egg. To this regard sperm need exceptionally more ATP than any other cell (Miki 2007) expecially after ejaculation in the female reproductive tract and after the starting of capacitation that is characterized by a typical "hyperactivated" motility and by the acquisition of the ability to undergo the acrosome reaction (Yanagimachi 1994).

During the last decades one of the long lasting debate accompanying the study of sperm physiology focused on the main biochemical metabolic pathways necessary for energy supply. These aspects have been recently reviewed by different authors (Miki 2007; Ruiz-Pesini 2007). There are two pathways for ATP production in mammalian sperm, i.e. glycolysis and oxidative phosphorylation (Miki 2007; Ruiz-Pesini et al 2007). Much of the experimental data have demonstrated that these biochemical pathways participate together to ATP production and they rely one on the other depending on the functional state of the cell (Miki 2007) and on external stimulation (Ruiz-Pesini et al 2007). Furthermore glycolysis and oxidative phosphorylation are one dependent on the other also because the products of the glycolysis are substrate for the oxidative phosphorylation (Miki 2007; Ruiz-Pesini et al 2007). Since glycolysis is not so efficient as the oxidative phosphorylation (that is 15 times more efficient than glycolysis) in the presence of oxygen, the oxidative 
phosphorylation appears to be the preferred pathway for ATP production in sperm (Ruiz-Pesini et al 2007). On the other hand the fact that sperm, a cell that during its maturative progression from spermatogonium reduces dramatically its volume, retains such numerous, specialized and compartimentalized mitochondria in the middle piece, underline the importance of mitochondrial respiration as an important pathway for ATP production to maintain the efficiency of all energy consuming processes necessary for oocyte fertilization such as motility, capacitation, acrosome reaction and egg's penetration (Ruiz-Pesini et al 2007).

\section{Cannabinoids and energy metabolism}

Few Authors have suggested that mitochondria are involved in some cannabinoid actions above all when considering the effects of cannabinoids on cell apoptosis (Sarafian et al 2003; Jia et al 2006; Morimoto et al 2007). Very recently Athanasiou et al. (2007) have demonstrated that cannabinoids inhibit mitochondrial membrane potential, oxygen consumption and ATP production by inhibiting the mitochondrial respiratory chain. On the other hand the inhibitory effects of cannabinoids on mitochondrial respiration has long been known since '60-'70s when it was demonstrated that delta-9-tetrahydrocannabinol (THC), the main active cannabinoid compound contained in marijuana, inhibited oxygen consumption in rat brain homogenates and in liver mitochondria (Bose et al 1963; Mahoney 1972; Bartova et al 1976). For that concerning testicular cells, other studies performed in the early and late '80s have clearly shown that THC decrease glucose metabolism in testicular tissue thus inhibiting testicular glycolysis depriving the cells of their energy substrates leading to the disruption of testicular cell 
functions (Husain and Lamè 1981; Husain 1989). Other studies in different cell types have shown that THC alters mitochondrial function reducing cellular ATP levels in a time- and dose-dependent manner with effects observable at concentrations lower than $1 \mu \mathrm{M}$ and without any effect on cell viability indicating that ATP decline was not a consequent to death-induced cell permeability increase (Sarafian et al 2003)

\section{Endocannabinoids and energy metabolism in human sperm}

The precise mechanism(s) through which endocannabinoids inhibit sperm motility and other important functions as well as capacitation and acrosome reaction, has not been discovered yet but it seems very unprobable that endocannabinoids exert different inhibitory effects on each different sperm function (motility, capacitation, acrosome reaction) with different mechanisms of action. Thus an unifying hypothesis explaining the inhibitory effects of endocannabinoids on sperm function seems more feasible. Sperm motility, together with capacitation and acrosome reaction, are all energy consuming processes (Miki 2007; Ruiz-Pesini et al 2007).

It is well known that the kinetic activity of sperm results from the different components involved in motility activation as well as the integrity of all flagellar structural proteins, oxidation of energetic substrates and ATP production, transformation of chemical energy into mechanical movement, the activity of all enzymes involved in the flagellar beating. The decline in mitochondrial activity would be expected to decrease energy supply thus affecting different sperm functions as well as motility but also capacitation and acrosome reaction. 
If endocannabinoids inhibit energy metabolism in sperm as described for other cell types, then it could be possible that the inhibition of all sperm functions by endocannabinoids could origin from the same mechanism of action, i.e. the decrease of the energetic reserves on which all these processes rely. To this respect we have previously demonstrated that AEA induced a dose-dependent decrease of the sperm mitochondrial activity (Rossato et al 2005) that paralleled the reduction of sperm motility without affecting viability up to concentrations as high as $1 \mu \mathrm{M}$ (figure 1-2). Furthermore also capacitation and acrosome reaction are inhibited by endocannabinoids as previously demonstrated (Rossato et al 2005) and reported in figure 3.

Many hypotheses may explain the inhibitory effects of endocannabinoids on mitochondrial function: endocannabinoids may interfere with mitochondrial electron transport (Fusi et al 1992; Wallace et al 1997), mitochondrial activity via depletion of NADH as previously shown (Sarafian et al 2003), mitochondrial permeability transition pore complex as recently suggested (Sarafian et al 2003). The possible interference of endocannabinoids with glucose uptake and utilization for ATP production as previously suggested by experimental studies utilizing testicular extracts more that 25 years ago (Husain and Lamè 1981), seems not plausible since in many different cell types endocannabinoids have been shown to increase glucose uptake instead of decrease it as we have recently demonstrated in human adipocytes (Pagano et al 2007) confirming recent observations in rat 3T3-L1 adipocytes (Gasperi et al 2007).

\section{Conclusions}


There is a general consensus derived from strong experimental data indicating that endocannabinoids exert inhibitory effects on many fundamental functions in sperm from different species. Although different hypotheses have been proposed to explain the mechanism(s) of action of these compounds in sperm inhibition, to date there is no definitive data on what is the precise target altered by endocannabinoids. Given the wide range of inhibitory effects induced by endocannabinoids in sperm we have tried to identify a possible "large" common mechanism of action inhibiting all sperm functions. The data regarding the inhibitory effects of endocannabinoids on mitochondrial activity in different cell types and the demonstration that these substances reduce mitochondrial activity also in human sperm let us to hypothize that mitochondrion could be the main target of endocannabinoids with consequent reduction of energy reserves thus inhibiting all sperm energy consuming processes such as motility, capacitation and acrosome reaction. 


\section{References}

Athanasiou, A., Clarke, A.B., Turner, A.E., Kumaran, N.M., Vakilpour, S., Smith, P.A., Bagiokou, D., Bradshaw, T.D., Westwell, A.D., Fang, L., Lobo, D.N., Constantinescu, C.S., Calabrese, V., Loesch, A., Alexander, S.P., Clothier, R.H., Kendall, D.A., Bates, T.E., 2007. Cannabinoid receptor agonists are mitochondrial inhibitors: a unified hypothesis of how cannabinoids modulate mitochondrial function and induce cell death. Biochem. Biophys. Res. Commun. 364, 131-7.

Bartova, A., Birmingham, M.K., 1976. Effect of delta9-tetrahydrocannabinol on mitochondrial NADH-oxidase activity. J. Biol. Chem. 251, 5002-5006.

Beltrán, C., Vacquier, V.D., Moy, G., Chen, Y., Buck, J., Levin, L.R., Darszon, A., 2007. Particulate and soluble adenylyl cyclases participate in the sperm acrosome reaction. Biochem. Biophys. Res. Commun. 358, 1128-1135.

Bose, B.C., Saifi, A.Q., Bhsgwat, A.W., 1963. Effect of cannabis indica on hexobarbital sleeping time and tissue respiration of rat brain. Arch. Int. Pharmacodyn. Ther. 141, 520-524.

Cobellis, G., Cacciola, G., Scarpa, D., Meccariello, R., Chianese, R., Franzoni, M.F., Mackie, K., Pierantoni, R., Fasano, S., 2006. Endocannabinoid system in frog and rodent testis: type-1 cannabinoid receptor and fatty acid amide hydrolase activity in male germ cells. Biol. Reprod. 75, 82-89. 
Darszon, A., Labarca, P., Nishigaki, T., Espinosa, F., 1999. Ion channels in sperm physiology. Physiol. Rev. 79, 481-510.

De Jonge, C.J., Han, H.L., Lawrie, H., Mack, S.R., Zaneveld, L.J., 1991. Modulation of the human sperm acrosome reaction by effectors of the adenylate cyclase/cyclic AMP second-messenger pathway. J. Exp. Zool. 258, 113-125.

Di Marzo, V., 2006. A brief history of cannabinoid and endocannabinoid pharmacology as inspired by the work of British scientists. Trends Pharmacol. Sci. $200627,134-140$.

Di Marzo, V., De Petrocellis, L., Bisogno, T., 2005. The biosynthesis, fate and pharmacological properties of endocannabinoids. Handb. Exp. Pharmacol. 168, 147-185.

Felder, C.C., Glass, M., 1998. Cannabinoid receptors and their endogenous agonists. Annu. Rev. Pharmacol. Toxicol. 38, 179-200.

Foresta, C., Rossato, M., 1997. Calcium influx pathways in human spermatozoa. Mol. Hum. Reprod. 3, 1-4.

Fusi, F., Sgaragli, G., Murphy, M.P., 1992. Interaction of butylated hydroxyanisole with mitochondrial oxidative phosphorylation. Biochem. Pharmacol. 43, 1203-1208. 
Gasperi. V., Fezza, F., Pasquariello, N., Bari, M., Oddi, S., Finazzi Agrò, A., Maccarrone, M., 2007. Endocannabinoids in adipocytes during differentiation and their role in glucose uptake. Cell. Mol. Life Sci. 64, 219-229.

Gérard, C.M., Mollereau, C., Vassart, G., Parmentier, M., 1991. Molecular cloning of a human cannabinoid receptor which is also expressed in testis. Biochem. J. 279, 129-134.

Hembree, W.C. 3rd., Nahas, G.G., Zeidenberg, P., Huang, H.F., 1978. Changes in human spermatozoa associated with high dose marihuana smoking. Adv. Biosci. 22-23, 429-439.

Husain, S., 1989. Effects of delta-9-tetrahydrocannabinol on in vitro energy substrate metabolism in mouse and rat testis. Physiol. Behav. 46, 65-68.

Husain, S., Lamé, M.W., 1981. Inhibitory effects of delta 9-tetrahydrocannabinol on glycolytic substrates in the rat testis. Pharmacology 23, 102-112.

Jia, W., Hegde, V.L., Singh, N.P., Sisco, D., Grant, S., Nagarkatti, M., Nagarkatti, P.S., 2006. Delta9-tetrahydrocannabinol-induced apoptosis in Jurkat leukemia T cells is regulated by translocation of bad to mitochondria. Mol. Cancer Res. 4, 549-562.

Maccarrone, M., Barboni, B., Paradisi, A., Bernabò, N., Gasperi, V., Pistilli, M.G., Fezza, F., Lucidi, P., Mattioli, M., 2005. Characterization of the endocannabinoid 
system in boar spermatozoa and implications for sperm capacitation and acrosome reaction. J. Cell. Sci. 118, 4393-4404.

Mahoney, J.M., Harris, R.A., 1972. Effect of 9 -tetrahydrocannabinol on mitochondrial precesses. Biochem. Pharmacol. 21, 1217-1226.

Miki, K., 2007. Energy metabolism and sperm function. Soc. Reprod. Fertil. Suppl. 65, 309-325.

Morimoto, S., Tanaka, Y., Sasaki, K., Tanaka, H., Fukamizu, T., Shoyama, Y., Shoyama, Y., Taura, F., 2007. Identification and characterization of cannabinoids that induce cell death through mitochondrial permeability transition in Cannabis leaf cells. J. Biol. Chem. 282, 20739-20751.

Pagano, C., Pilon, C., Calcagno, A., Urbanet, R., Rossato, M., Milan, G., Bianchi, K., Rizzuto, R., Bernante, P., Federspil, G., Vettor, R., 2007. The Endogenous Cannabinoid System Stimulates Glucose Uptake in Human Fat Cells via Phosphatidylinositol 3-Kinase and Calcium-Dependent Mechanisms. J. Clin. Endocrinol. Metab. 92, 4810-4819.

Perez, L.E., Smith, C.G., Asch, R.H., 1981. Delta 9-tetrahydrocannabinol inhibits fructose utilization and motility in human, rhesus monkey, and rabbit sperm in vitro. Fertil. Steril. 35, 703-705. 
Pertwee, R.G., 1997. Pharmacology of cannabinoid CB1 and CB2 receptors. Pharmacol. Ther. 74, 129-180.

Ricci, G., Cacciola, G., Altucci, L., Meccariello, R., Pierantoni, R., Fasano, S., Cobellis, G., 2006. Endocannabinoid control of sperm motility: the role of epididymus. Gen. Comp. Endocrinol. 153, 320-322.

Rossato, M., Ion Popa, F., Ferigo, M., Clari, G., Foresta, C., 2005. Human sperm express cannabinoid receptor $\mathrm{Cb}$ l, the activation of which inhibits motility, acrosome reaction, and mitochondrial function. J. Clin. Endocrinol. Metab. 90, 984-991.

Ruiz-Pesini, E., Díez-Sánchez, C., López-Pérez, M.J., Enríquez, J.A., 2007. The role of the mitochondrion in sperm function: is there a place for oxidative phosphorylation or is this a purely glycolytic process? Curr. Top. Dev. Biol. 77, 3-19.

Salicioni, A.M., Platt, M.D., Wertheimer, E.V., Arcelay, E., Allaire, A., Sosnik, J., Visconti, P.E., 2007. Signalling pathways involved in sperm capacitation. Soc. Reprod. Fertil. Suppl. 65, 245-259.

Sarafian, T.A., Kouyoumjian, S., Khoshaghideh, F., Tashkin, D.P., Roth, M.D., 2003.

Delta 9-tetrahydrocannabinol disrupts mitochondrial function and cell energetics. Am. J. Physiol. Lung. Cell. Mol. Physiol. 284, L298-L306. 
Schuel, H., Goldstein, E., Mechoulam, R., Zimmerman, A.M., Zimmerman, S., 1994. Anandamide (arachidonylethanolamide), a brain cannabinoid receptor agonist, reduces sperm fertilizing capacity in sea urchins by inhibiting the acrosome reaction. Proc. Natl. Acad. Sci. U.S.A, 91, 7678-7682.

Schuel, H., Burkman, L.J., Lippes, J., Crickard, K., Mahony, M.C., Giuffrida, A., Picone, R.P., Makriyannis, A., 2002a. Evidence that anandamide-signaling regulates human sperm functions required for fertilization. Mol. Reprod. Dev. 63, 376-387.

Schuel, H., Burkman, L.J., Lippes, J., Crickard, K., Forester, E., Piomelli, D., Giuffrida, A., 2002b. N-Acylethanolamines in human reproductive fluids. Chem. Phys. Lipids $121,211-227$.

Wallace, K.B., Eells, J.T., Madeira, V.M., Cortopassi, G., Jones, D.P., 1997. Mitochondria-mediated cell injury. Symposium overview. Fundam. Appl. Toxicol. 38, 23-37

Wassarman, P.M., Jovine, L., Qi, H., Williams, Z., Darie, C., Litscher, E.S., 2005. Recent aspects of mammalian fertilization research. Mol. Cell. Endocrinol. 234, 95-103.

Whan, L.B., West, M.C., McClure, N., Lewis, S.E., 2006. Effects of delta-9 tetrahydrocannabinol, the primary psychoactive cannabinoid in marijuana, on human sperm function in vitro. Fertil. Steril. 85, 653-60. 
Yanagimachi, R., 1994. Mammalian fertilization. In: Knobil, E., Neill, J.D. (eds.), The Physiology of Reproduction. Raven Press, New York, pp. 189-281.

\section{Legend to figures}

Figure 1. Effects of anandamide (AEA) on mitochondrial function in human sperm. On the left side of the figure are reported the typical patterns of fluorescence of sperm aliquots after rhodamine 123 staining from control samples (A, vehicle only), sperm samples treated with AEA $0.1 \mu \mathrm{M}$ (B), $1.0 \mu \mathrm{M}$ (C) and $10 \mu \mathrm{M}$ (D). The numbers in each panel indicate the percentage of sperm within the peak with the highest rhodamine 123 (R-123) fluorescence (M2), representing cells with the highest mitochondrial activity with respect to sperm with the lowest mitochondrial activity grouped within the region labeled as $M 1$. On the right side of the figure, the 
percentages of sperm cells within the peak with the highest R-123 fluorescence (M2), have been coupled to the percentages of sperm viability and motility observed after incubation with the corresponding AEA concentration in three separate experiments. ${ }^{*} \mathrm{P}<0.01,{ }^{* *} \mathrm{P}<0.001$ vs control samples. (From Rossato et al 2005).

Figure 2. Effects of anandamide (AEA) on human sperm motility and viability. A. Sperm were incubated in the absence ( $\mathbf{\Delta}$ ) and presence (-) of AEA at different concentrations. For the evaluation of the effects of the CBI-R antagonist SR 141716 on AEA-induced modifications of sperm motility, sperm were pre-incubated in the presence of equimolar SR 141716 concentration for 45 mins before AEA addition 1. Sperm incubation with SR141716 alone did not induce any significant modification of sperm motility $(\bullet)$. Data are expressed as percentages of total motile sperm. ${ }^{*} P<0.01,{ }^{* * P}<0.001$ vs control and SR 141716-pretreated samples. B. Sperm were incubated in the absence ( $\mathbf{\Delta}$ ) and presence (-) of AEA at different concentrations. For the evaluation of the effects of the CBI-R antagonist SR 141716 in AEA effects on sperm viability, sperm were pre-incubated in the presence of equimolar SR 141716 concentration for 45 mins before AEA addition ( $\bullet$ ). Sperm incubation with SR 141716 alone did not induce any significant modification of sperm viability $(\bullet)$. Data are expressed as percentages of viable sperm. ${ }^{*} P<0.01$, ${ }^{* * P}<0.001$ vs control and SR 141716-pretreated samples. (From Rossato et al 2005).

Figure 3. Effects of anandamide (AEA) on acrosome reaction in fresh and capacitated human sperm. A. Isolated motile human sperm were incubated in the 
absence (Ctrl) and presence of AEA (1.0 $\mu \mathrm{M})$ and in the presence of ionomycin, a well known acrosome reaction inducer (iono, $1.0 \mu \mathrm{M}$ ), for 60 mins before acrosome reaction evaluation. B. Sperm were incubated in control medium and in capacitating conditions for 6 hours (Capac) in the absence and presence of AEA (1.0 $\mu \mathrm{M})$ before acrosome reaction evaluation.

${ }^{*} \mathrm{P}<0.01$ vs control; ${ }^{* *} \mathrm{P}<0.01$ vs AEA-treated samples; $\# \mathrm{P}<0.05$ vs control and AEAtreated samples. (From Rossato et al 2005). 

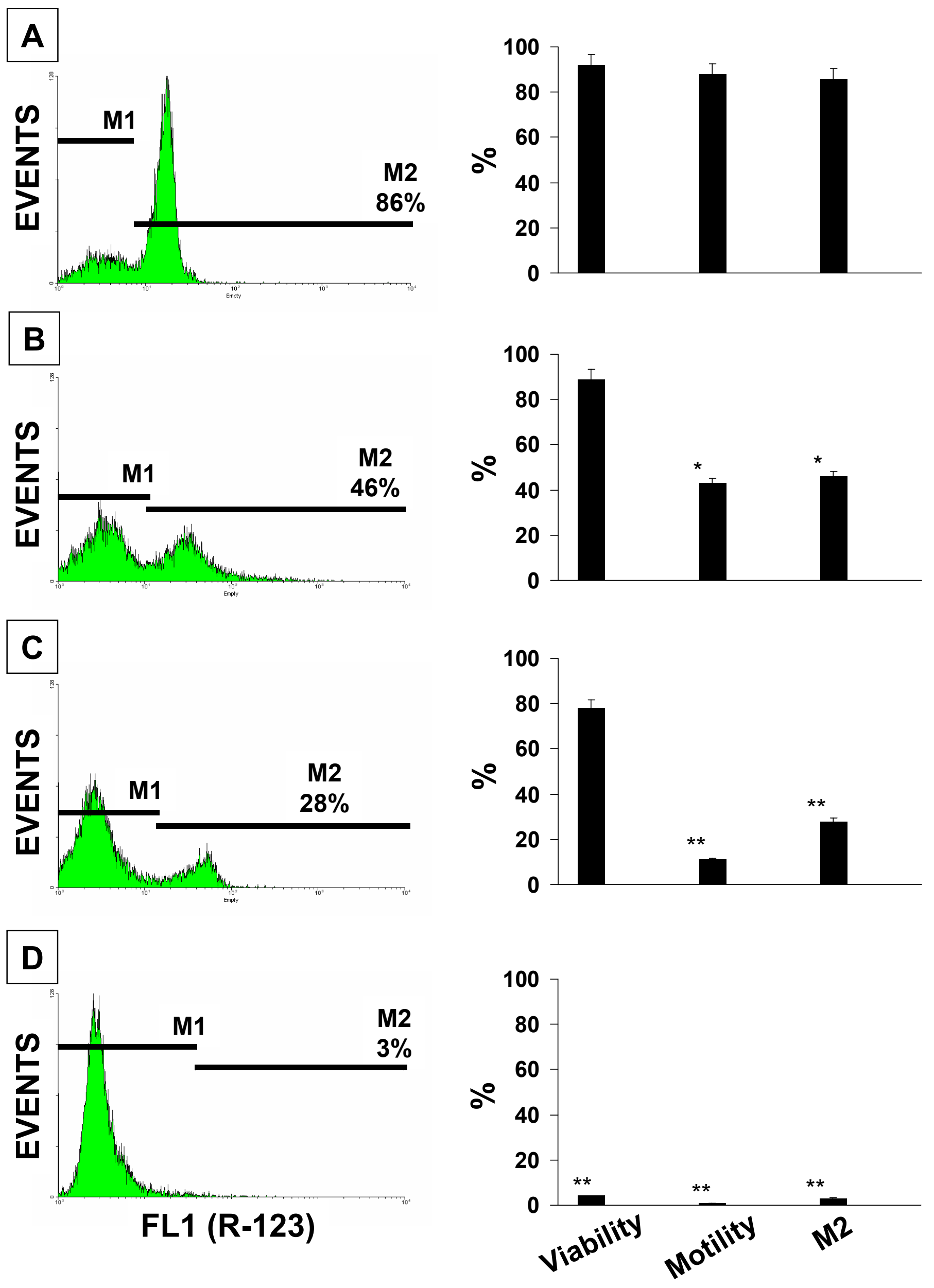

rage 222 of 24 


\section{A}

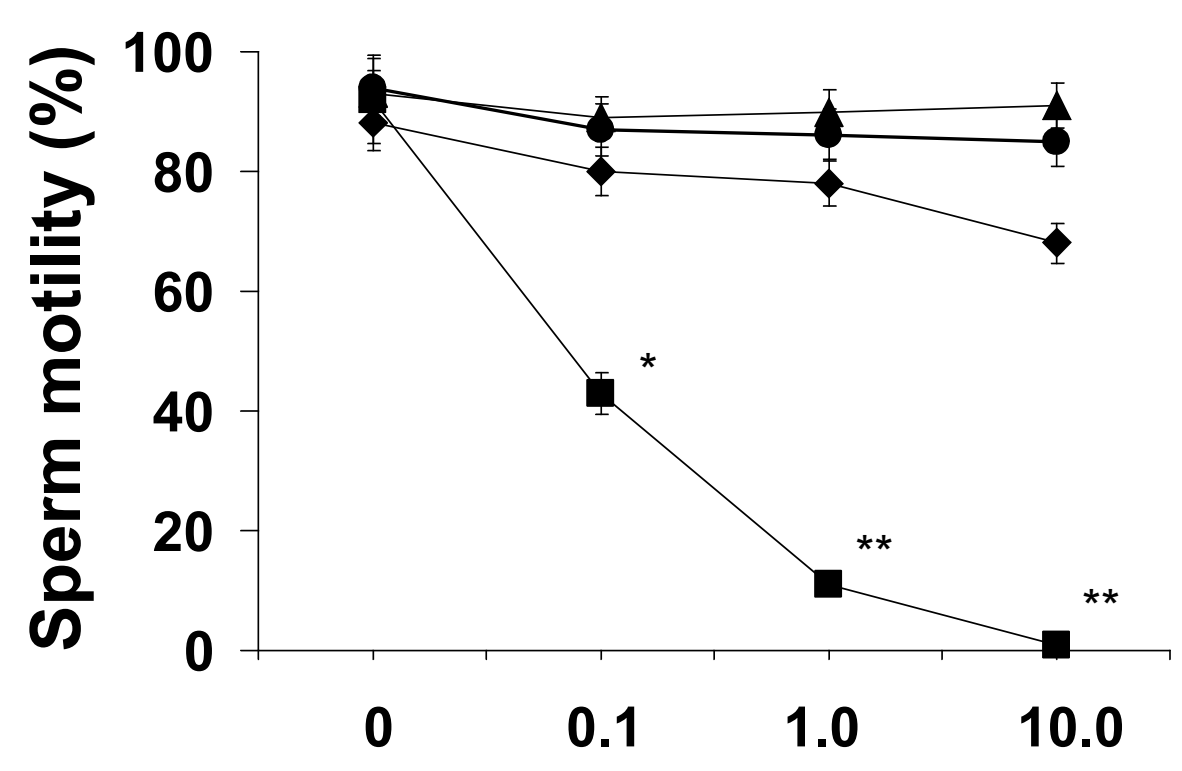

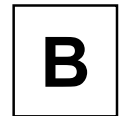

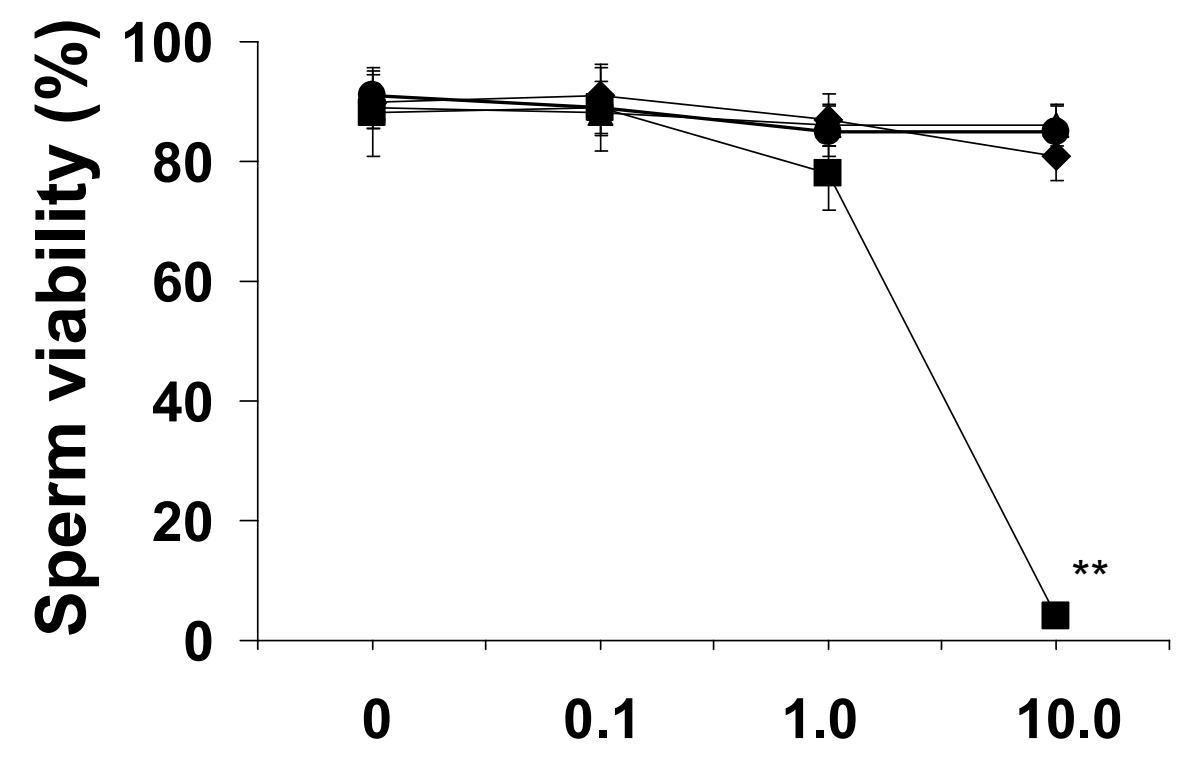

[Anandamide] $\mu \mathrm{M}$ 
A

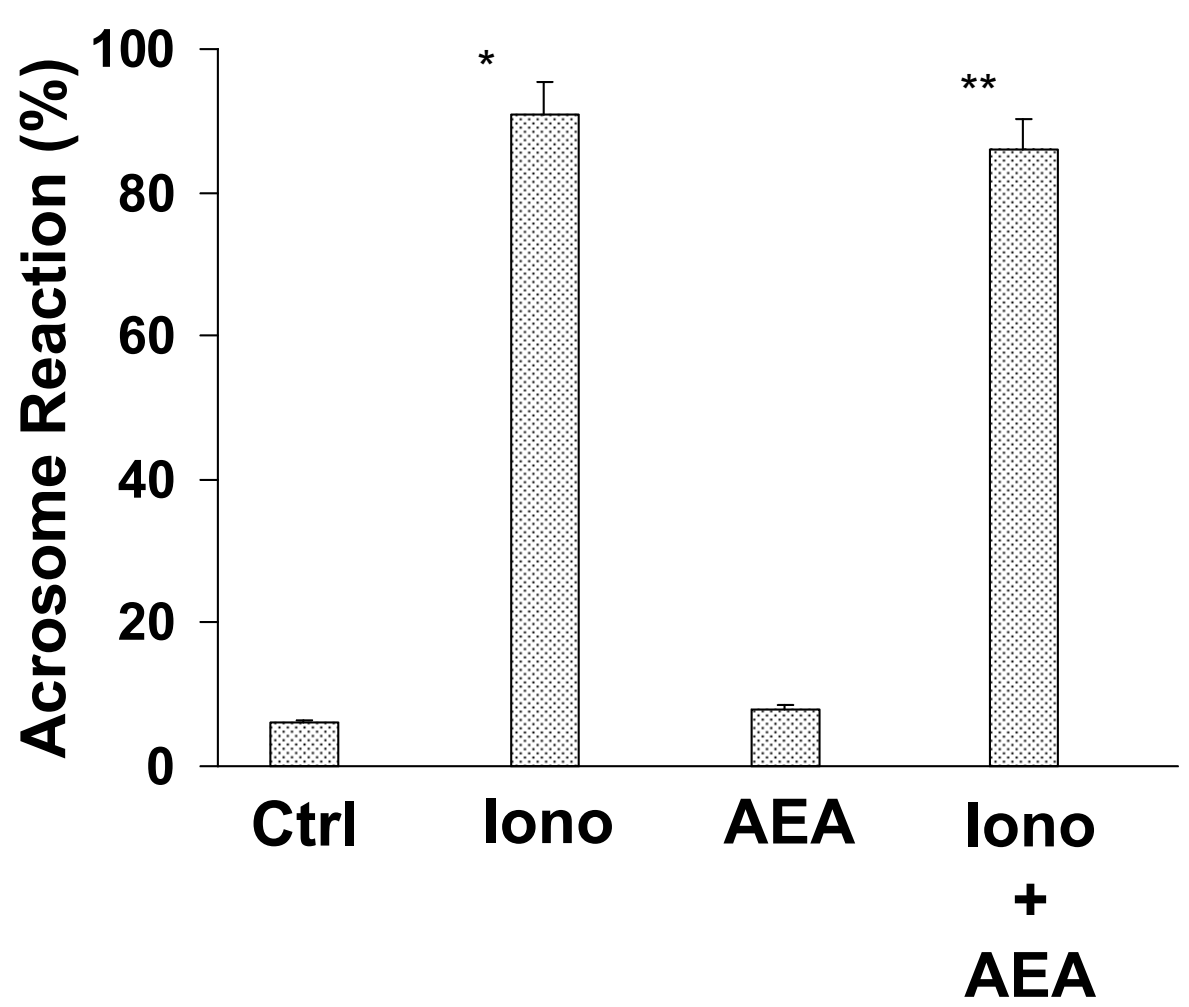

B

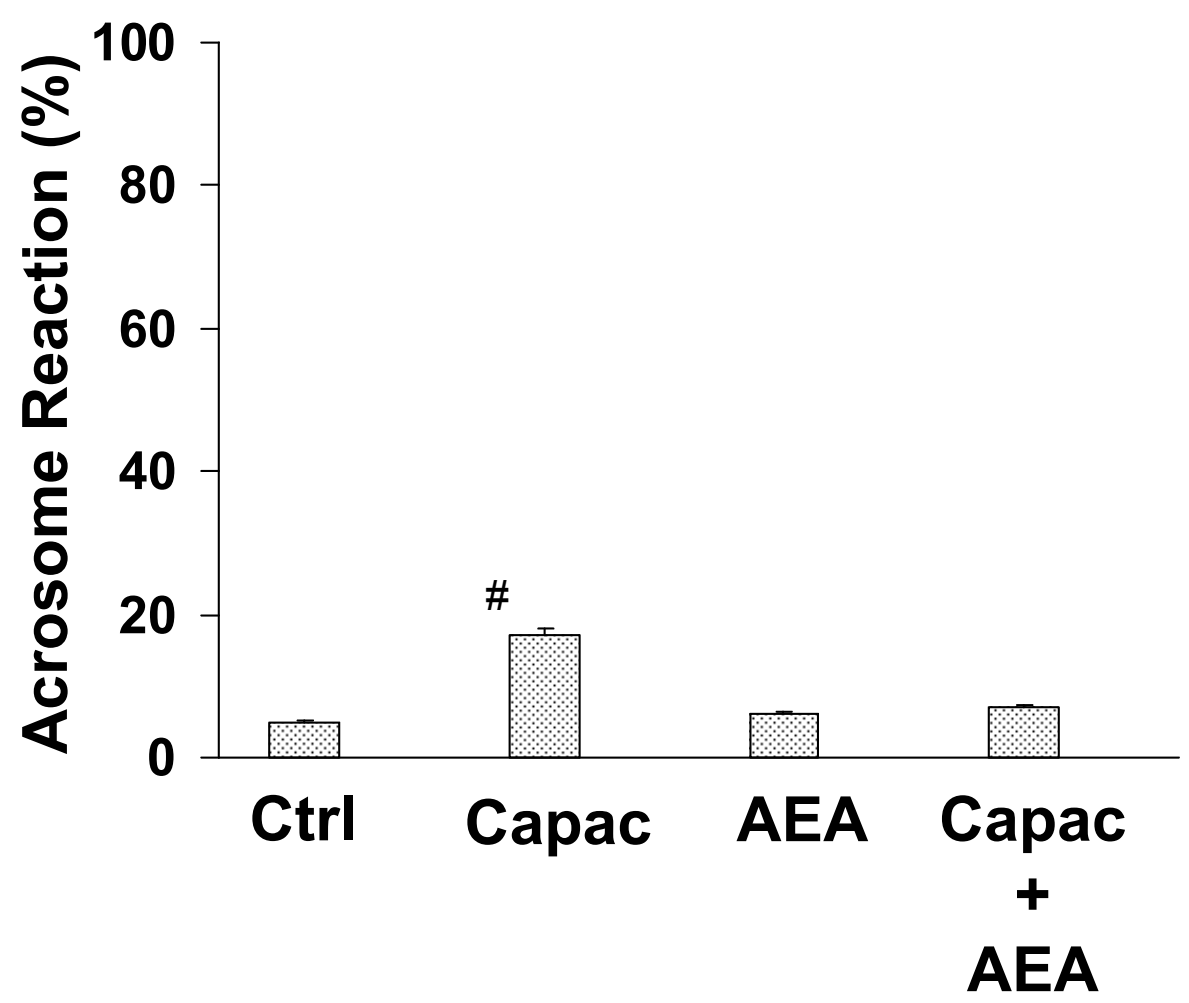

